\title{
Fibroblast Growth Factor 2 (FGF-2) Promotes Acquisition of Epidermal Growth Factor (EGF) Responsiveness in Mouse Striatal Precursor Cells: Identification of Neural Precursors Responding to both EGF and FGF-2
}

\author{
Francesca Ciccolini ${ }^{1}, 2$ and Clive N. Svendsen ${ }^{1}$ \\ ${ }^{1}$ Medical Research Council Cambridge Centre for Brain Repair, Cambridge CB2 2PY, England, and 2 Medical Research \\ Council Laboratory of Molecular Biology, Cambridge CB2 2QH, England
}

Epidermal growth factor (EGF) and fibroblast growth factor 2 (FGF-2) induce the proliferation of neural precursor cells isolated from specific regions of the embryonic and adult brain. However, the lineage relationship between the EGF- and FGF2-responsive cells is unknown. In this study we used phosphorylation of the transcription factor cAMP response elementbinding protein as a functional readout to identify cells responding to EGF and FGF-2. In primary cultures of mouse embryonic day 14 (E14) striatum, maintained in vitro for $24 \mathrm{hr}$, $12 \%$ of the cells responded to FGF-2, whereas no response to EGF could be detected. Seventy-five percent of these FGF-2responsive cells were $\beta$ tubulin III (TuJ1)-positive neurons, and $25 \%$ expressed nestin, a marker for neuroepithelial precursors.
After growth factor treatment for $6 \mathrm{~d}$, a population of nestinpositive cells responding to both EGF and FGF-2 were identified. The 6-d-old cultures also contained a small number of TuJ1-positive cells that responded to FGF-2 only. Priming of striatal cells for $24 \mathrm{hr}$ with FGF-2 but not with EGF was sufficient to induce the appearance of EGF- and FGF-2 responsive cells after only $2 \mathrm{~d}$ in vitro. Thus, neural precursor cells from the mouse E14 striatum initially responding to FGF-2 only acquire EGF responsiveness later during in vitro development. At this stage EGF and FGF-2 act on the same cells. The acquisition of EGF responsiveness is promoted by FGF-2.

Key words: stem cells; progenitors; growth factors; CREB phosphorylation; embryonic brain; neural development
The discovery of neural precursors with the ability both to selfrenew and to generate progenitors for neurons, astrocytes, and oligodendrocytes in vitro (Cattaneo and McKay, 1991; Reynolds and Weiss, 1992; Temple and Davis, 1994) provides a powerful model for examining cellular mechanisms underlying the development of the CNS. Neural precursors could also provide a source of tissue for clinical transplantation programs that may in the future lead to novel therapeutic approaches for treating neuronal loss associated with neurodegenerative conditions such as Parkinson's and Huntington's diseases (Lindvall, 1997; Svendsen, 1997).

A number of growth factors support the proliferation of neural precursor cells and the differentiation of their progenitors. In particular, epidermal growth factor (EGF) and fibroblast growth factor 2 (FGF-2) have been found to stimulate the division of embryonic or adult CNS precursors (for review, see Gage et al., 1995; Kilpatrick et al., 1995; McKay, 1997; Weiss et al., 1996). However, their relative importance in inducing a mitogenic response is controversial. EGF has been shown to induce the proliferation of multipotent precursor cells from either embryonic or adult mouse striatum, leading to formation of cell clusters termed neurospheres (Reynolds and Weiss, 1992; Reynolds et al., 1992), whereas FGF-2 may act on lineage-restricted progenitors

Received May 15, 1998; revised July 21, 1998; accepted July 21, 1998.

This work was funded by the European Community and the Wellcome Trust. We thank Dr. Hilmar Bading for discussion and help with this manuscript and Dr. Neil Scolding for the Gal-C antibody.

Correspondence should be addressed to Dr. Francesca Ciccolini, Medical Research Council Cambridge Centre for Brain Repair, Forvie Site, Robinson Way, Cambridge CB2 2PY, England.

Copyright (C) 1998 Society for Neuroscience $\quad 0270-6474 / 98 / 187869-12 \$ 05.00 / 0$ present in these EGF-generated neurospheres (Vescovi et al., 1993). Other studies, however, have shown that FGF-2 can also induce the proliferation of multipotent precursor cells from adult striatum (Gritti et al., 1996), spinal cord (Weiss et al., 1996a; Shihabuddin et al., 1997), or both adult and embryonic hippocampus and embryonic cortex (Gensburger et al., 1987; Ray et al., 1993; Johe et al., 1996; Qian et al., 1997). These studies could indicate the existence of a distinct population of multipotent precursor cells responding to either EGF or FGF-2. Alternatively, it is possible that these cells respond to both EGF and FGF-2 and that their proliferative response to either growth factor depends on experimental conditions.

To investigate whether EGF and FGF-2 act on the same or distinct cell populations and to analyze the lineage relationship between growth factor-responsive cells, we characterized individual EGF- and FGF-2-responsive cells derived from mouse embryonic day 14 (E14) striatum. Because it has been difficult to assess growth factor receptor expression in individual cells, we have developed a new approach to functionally detect cells responding to EGF or FGF-2. Both growth factor receptors act on classical receptor tyrosine kinases that induce the activation of the Ras/extracellular signal-regulated kinase (ERK) pathway (Marshall, 1995). One well characterized intracellular consequence of this event is the phosphorylation of the transcription factor cAMP response element-binding protein (CREB) on serine 133 (Ginty et al., 1994; Xing et al., 1996). This phosphorylation can be detected immunocytochemically using an antibody that specifically recognizes the phosphorylated form of CREB (phospho-CREB) (Ginty et al., 1993). In this study CREB phosphorylation was used as a functional readout for EGF and FGF-2 

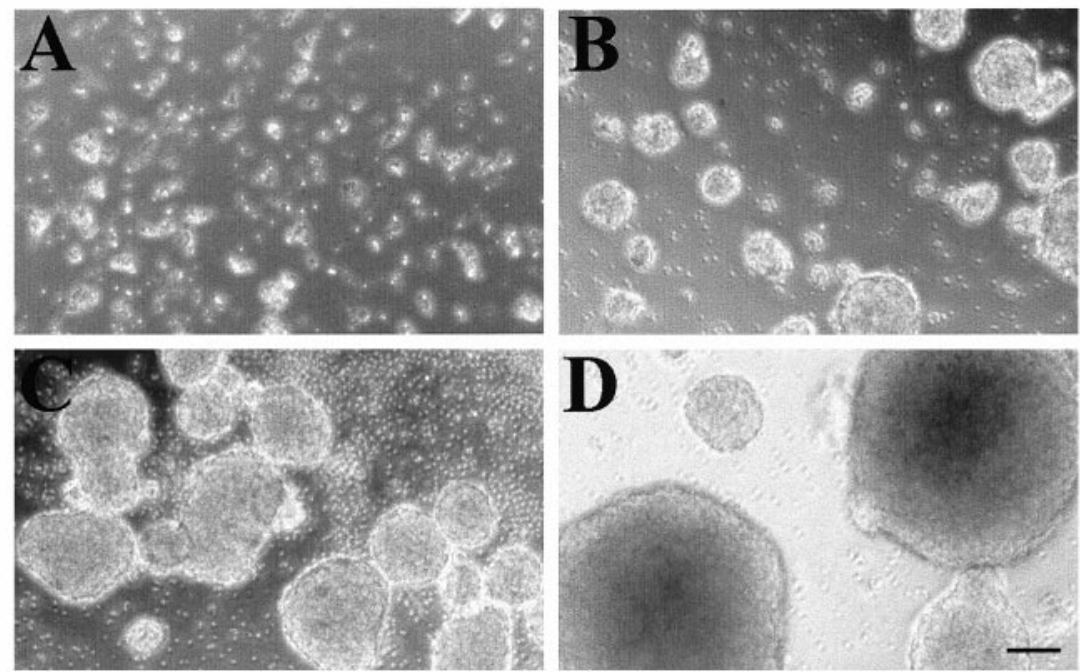

$\mathbf{F}$

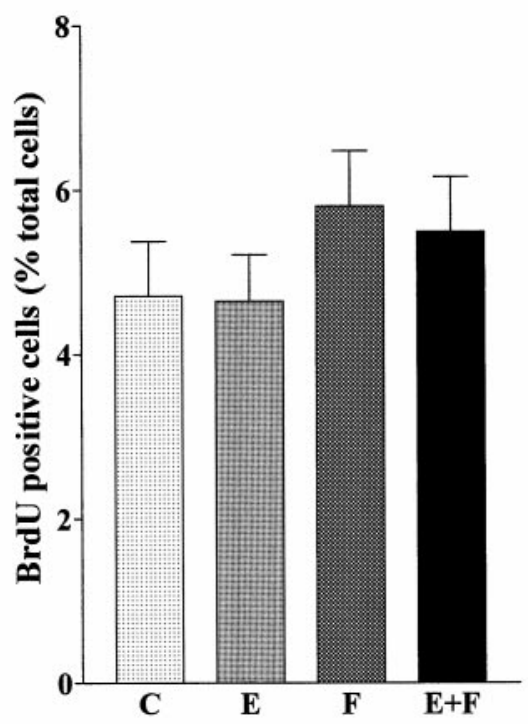

G

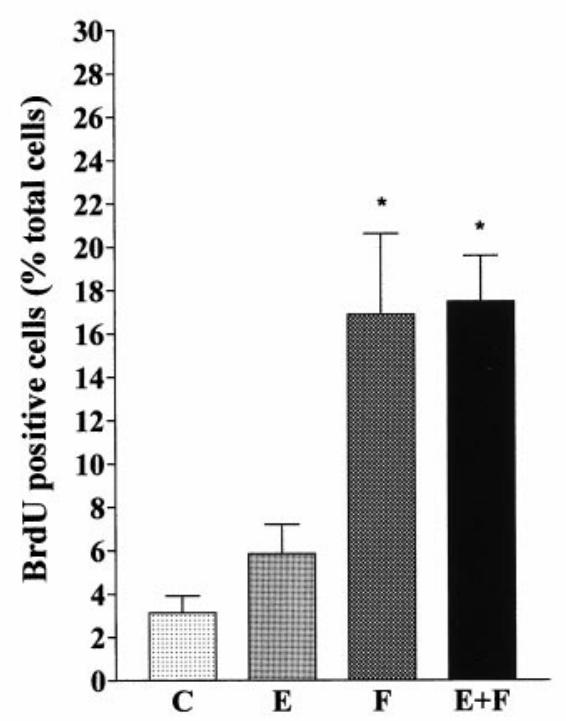

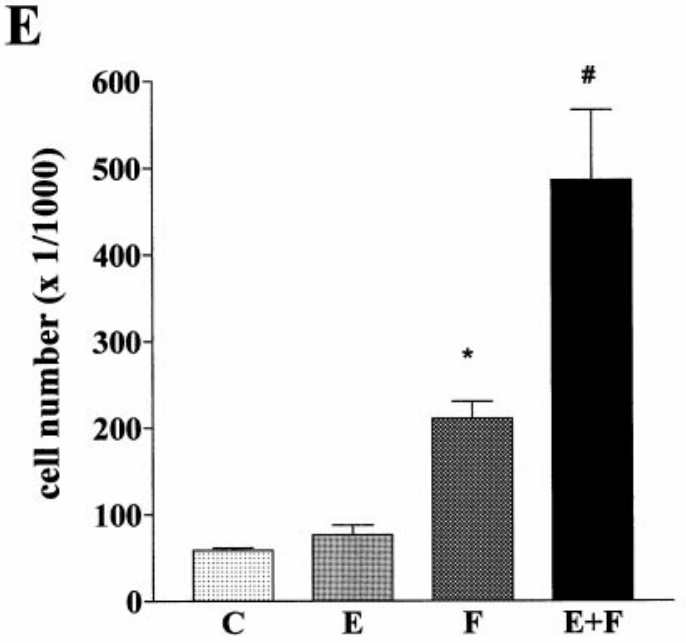

$\mathbf{H}$

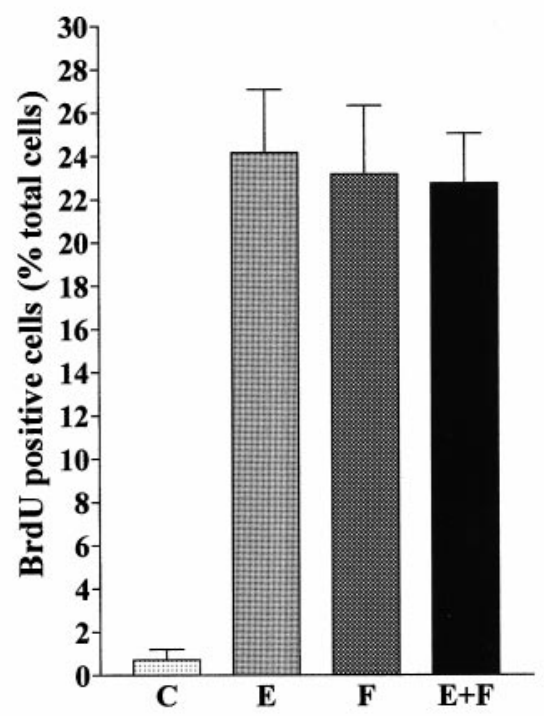

Figure 1. Effects of different growth factor conditions on mouse E14 striatal cells. $A-D$, Photographs of neurospheres present in cultures grown for $7 \mathrm{~d}$ without EGF and FGF-2 $(A)$ or in the presence of EGF $(B)$, FGF-2 $(C)$, or EGF plus FGF-2 $(D)$. $E$, Number of viable cells in cultures of striatal cells grown as neurospheres for $7 \mathrm{~d}$ in the presence of the indicated growth factors. Data represent the means of seven independent experiments. $F-H$, Rate of BrdU incorporation in striatal cells grown in vitro for $1(F), 3(G)$, and $6(H) \mathrm{d}$ in the presence of the indicated growth factors. Data represent the means of four different experiments. $E$, ${ }^{\#}$ Significantly different from EGF and FGF $(p<0.001)$. $G$, *Significantly different from EGF and control $(p<0.001)$.

Table 1. Effects of growth factor treatment on size and number of neurospheres

\begin{tabular}{lccc} 
& EGF & FGF-2 & EGF + FGF-2 \\
\hline Small & $85.0 \pm 17.0$ & $110.4 \pm 17.8$ & $162.1 \pm 33.6$ \\
Medium & $11.2 \pm 3.1$ & $41.2 \pm 9.3$ & $44.5 \pm 6.0$ \\
Large & $2.1 \pm 0.9$ & $4.2 \pm 1.0$ & $12.4 \pm 2.3$ \\
Total no. & $98.6 \pm 18.9$ & $155.8 \pm 0.8$ & $219.0 \pm 38.9$ \\
\hline
\end{tabular}

Cells were grown for $6 \mathrm{~d}$ in vitro in the presence of the indicated growth factors. Values represent means \pm SEM of counts obtained from eight different experiments. cell responsiveness and was combined with the characterization of the cellular phenotype in double-immunostaining experiments using antibodies to either nestin, as a marker for precursor cells, or $\mathrm{TuJ} 1$, as a marker for neurons.

\section{MATERIALS AND METHODS}

Culture of primary embryonic striatal cells. Striata from E14 CD1 albino mouse embryos (plug day $=1.0)$ (Charles River Laboratories, Wilmington, MA) were dissected and transferred into ice-cold culture medium consisting of: DMEM/F12 (1:1; Life Technologies, Costa Mesa, CA), glucose $(0.6 \%)$, glutamine $(2 \mathrm{~mm}), \mathrm{NaHCO}_{3}(3 \mathrm{~mm}), \mathrm{HEPES}$ buffer $(5$ mM) (all from Sigma, St. Louis, MO), and 2\% B27 supplement (Life Technologies). The tissue was gently triturated with a fire-polished Pasteur pipette, and $10^{6}$ cells were plated at a density of 200,000 cells $/ \mathrm{ml}$ in Corning (Corning, NY) T25 culture flasks or Nunc (Naperville, IL) four-well dishes in the above culture medium in the presence of EGF (Sigma) and/or FGF-2 (R \& D Systems, Minneapolis, MN) at a concentration of $20 \mathrm{ng} / \mathrm{ml}$ each. Half of the medium was replaced every $3 \mathrm{~d}$ with 
Table 2. Effects of growth factor conditions on expression of differentiation markers in E14 striatal cells

\begin{tabular}{llrrr} 
& nestin & TuJ1 & GFAP & Gal-C \\
\hline 1 DIV (5) & $46.9 \pm 4.7$ & $45.2 \pm 2.9$ & $<5$ & $<5$ \\
6 DIV EGF (4) & $64.5 \pm 3.2$ & $2.9 \pm 1.3$ & 0 & 0 \\
6 DIV FGF-2 (4) & $47.6 \pm 3.3$ & $15.6 \pm 3.8$ & $<1$ \\
6 DIV EGF + FGF-2(4) & $73.9 \pm 5.8$ & $4.3 \pm 0.8$ & 0 & $<1$ \\
6 DIV EGF + differentiation (4) & ND & $36.7 \pm 6.69$ & $62.4 \pm 3.8$ & $7.3 \pm 0.2$ \\
6 DIV FGF-2 + differentiation (4) & ND & $39.8 \pm 5.0$ & $64.5 \pm 7.4$ & $8.4 \pm 0.1$ \\
6 DIV EGF + FGF-2 + differentiation (4) & ND & $39.1 \pm 5.0$ & $8.3 \pm 0.35$
\end{tabular}

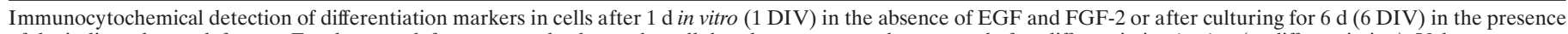

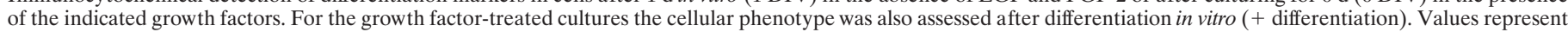
means of percent total cell \pm SEM; the number of experiments is indicated in parentheses. ND, Not detected.

fresh medium containing the same concentration of growth factors. After 6 or $7 \mathrm{~d}$, neurospheres were collected by centrifugation, resuspended in fresh medium, and triturated with a fire-polished Pasteur pipette as described above. This procedure gave rise to a mixture of single cells and small neurospheres. The number of viable cells in each culture was determined by the trypan blue exclusion technique.

To assess the effects of the different growth factor treatments on the size and number of neurospheres, mouse E14 striatal cells were plated onto 24 well plates (Nunc; 100,000 cells per well) and grown for $6 \mathrm{~d}$ in culture medium containing growth factors as described above. For each growth factor condition the total number of neurospheres, categorized into small, medium, and large size, was determined.

Antibodies. The following antibodies were used at the indicated dilution: mouse monoclonal antibody to nestin (PharMingen, San Diego, CA; 1:1000); mouse monoclonal antibody to $\beta$-tubulin type III (TuJ1; Sigma; 1:1000); mouse monoclonal antibody to galacto cerebrocidase (Gal-C; a gift from Dr. Neil Scolding, Neurology Unit, Cambridge University, England; 1:30); rabbit polyclonal antibody to glial fibrillary acidic protein (GFAP; Dako, High Wycombe, UK; 1:500); rabbit polyclonal antibody to CREB phosphorylated on serine 133 (Upstate Biotechnology, Lake Placid, NY; 1:1500), and mouse monoclonal antibody to bromodeoxyuridine (BrdU) (Boehringer Mannheim, Indianapolis, IN; 1:10).

Differentiation of the neurospheres. Mouse E14 striatal cells were grown for $6-7 \mathrm{~d}$ in the presence of EGF and/or FGF-2. From each culture 30-50 neurospheres were collected, rinsed in culture medium, and resuspended in culture medium containing $1 \%$ fetal calf serum (FCS). Cells were plated onto poly-L-lysine-laminin-coated chamber slides (Nunc), and their phenotype was determined immunocytochemically after $14 \mathrm{~d}$ using antibodies to TuJ1, GFAP, and Gal-C.

Growth factor stimulation. Striatal cells were plated $\left(50,000 \mathrm{cells} / \mathrm{cm}^{2}\right)$ either immediately after dissection or after $6 \mathrm{~d}$ of growth in vitro in the presence of EGF and/or FGF-2 onto poly-L-lysine-laminin-coated chamber slides (Nunc) in culture medium without EGF and FGF-2. Cells were stimulated $24 \mathrm{hr}$ after plating with EGF or FGF-2 $(20 \mathrm{ng} / \mathrm{ml}$ each $)$ or with a combination of both growth factors $(20 \mathrm{ng} / \mathrm{ml}$ each $)$. In some experiments a higher growth factor concentration $(40 \mathrm{ng} / \mathrm{ml}$ each) was used, which gave identical results. Cells were fixed after $7 \mathrm{~min}$ and processed for immunocytochemistry.

To analyze the effects of $24 \mathrm{hr}$ growth factor starvation and growth on a poly-L-lysine-laminin substrate on striatal cell proliferation, cells were plated immediately after dissection onto poly-L-lysine-laminin-coated four-well plates (Nunc; 100,000 cells per well). For each growth factor condition (EGF and/or FGF-2) two sets of cultures were established and compared: cultures to which growth factors were added at the time of plating and cultures to which growth factors were added $24 \mathrm{hr}$ after plating. After 5-6 d, clusters of growing cells were counted, and after $7 \mathrm{~d}$, cells were incubated with $0.025 \%$ trypsin (Sigma) for $5 \mathrm{~min}$, followed by addition of $10 \% \mathrm{FCS}$, and the total number of viable cells was determined.

Measurement of BrdU incorporation. The rate of BrdU incorporation was determined by adding $10 \mu \mathrm{M}$ BrdU (Boehringer Mannheim) to cultures of striatal cells grown for 1,3 , and $6 \mathrm{~d}$ either in the presence of EGF and/or FGF-2 (20 ng per $\mathrm{ml}$ each) or in the absence of exogenous growth factors. One hour after BrdU addition cells were collected, washed twice with culture medium, resuspended in culture medium, and plated onto poly-L-lysine-laminin-coated chamber slides (Nunc). Twenty minutes after plating cells were fixed and processed for immunocytochemistry. For BrdU-phospho-CREB double-immunostaining experiments, striatal cells grown for $6 \mathrm{~d}$ in growth factor-containing culture medium were collected by centrifugation and plated onto poly-L-lysinelaminin-coated chamber slides in culture medium (without exogenous growth factors) containing $10 \mu \mathrm{M}$ BrdU. After $24 \mathrm{hr}$ cells were stimulated with growth factors and processed for immunocytochemistry using the phospho-CREB and BrdU antibodies.

Immunocytochemistry. Cells were fixed in $4 \%$ paraformaldehyde in PBS containing $4 \%$ sucrose for 10 min, washed several times in PBS, permeabilized in NP-40 (0.05\% in PBS) for $5 \mathrm{~min}$, and blocked in goat serum (1.5\% in PBS) for $30 \mathrm{~min}$, all done at room temperature. Gal-C immunostaining was performed as described above, except that the cells were fixed for $20 \mathrm{~min}$ in ice-cold methanol. After fixing the cells were incubated with primary antibodies overnight at $4^{\circ} \mathrm{C}$. FITC-labeled secondary antibodies were used to visualize the signal. In doubleimmunostaining experiments, primary rabbit polyclonal antibodies were detected using a biotin-conjugated goat anti-rabbit secondary antibody and Cy3-conjugated streptavidin (Vector Laboratories, Burlingame, $\mathrm{CA}$ ); primary mouse monoclonal antibodies were detected using FITCconjugated goat anti-mouse antibody (Vector).

Cell counts and statistical analysis. To determine the number of growth factor-responsive cells, photographs of immunostained cells were taken using a high-resolution digital camera (Nikon). The number of cells showing nuclear phospho-CREB immunoreactivity was determined by counting the immunopositive and the total number of cells in four visual fields (100-400 cells per field). For antigens other than CREB, immunopositive cells were counted in four to seven visual fields (100-200 cells per field). The means and SEs of at least three independent experiments were calculated, and statistical significance test (ANOVA with post hoc Newman-Keuls) analyses were performed using a statistical package (Graphpad, Prism).

Table 3. Effects of $24 \mathrm{~h}$ growth factor starvation on proliferation of mouse E14 striatal cells

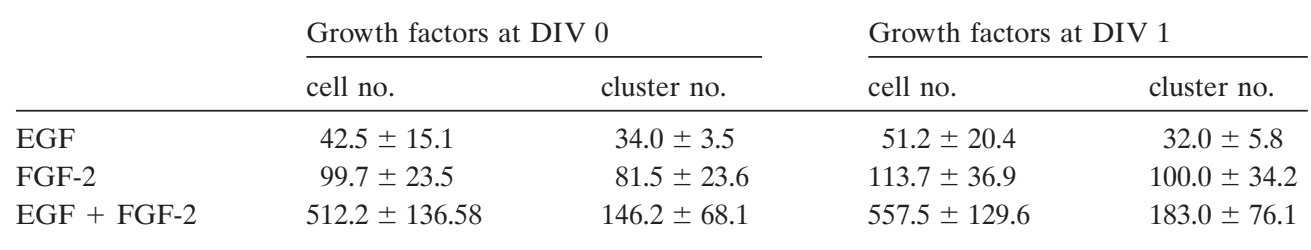

Striatal cells were plated onto a poly-L-lysine-laminin substrate. The indicated growth factors were added either at the time of plating (DIV 0) or $24 \mathrm{~h}$ after plating (DIV 1). Values represent means \pm SEM of total counts obtained from two different experiments. 


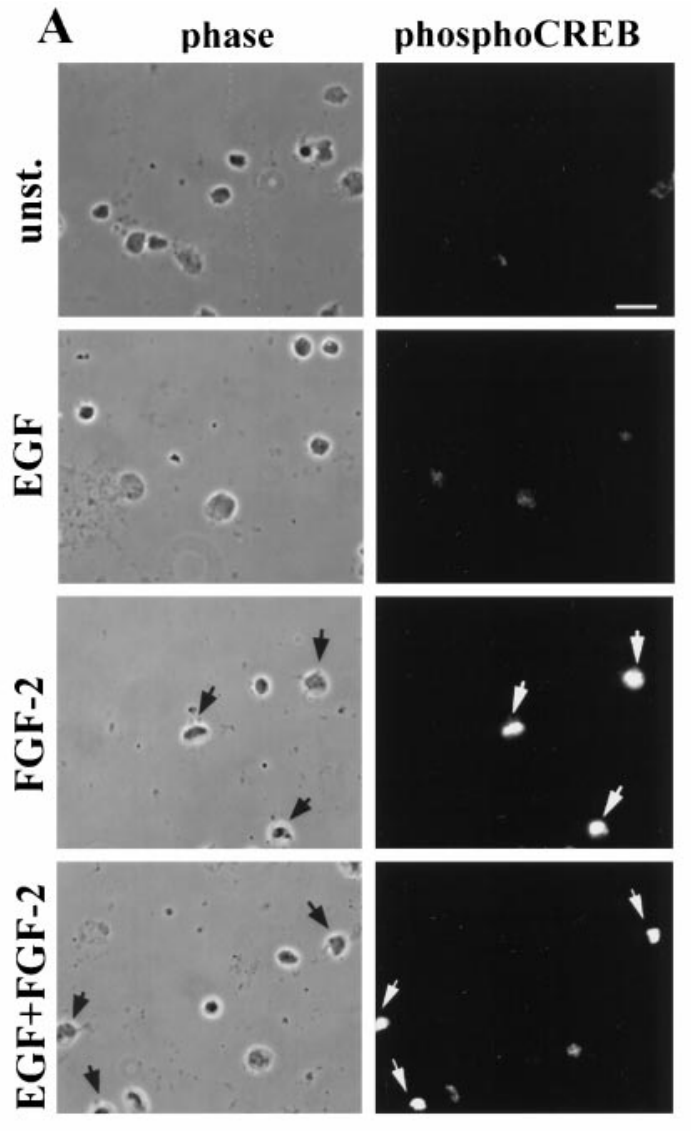

B

\section{4 hours}

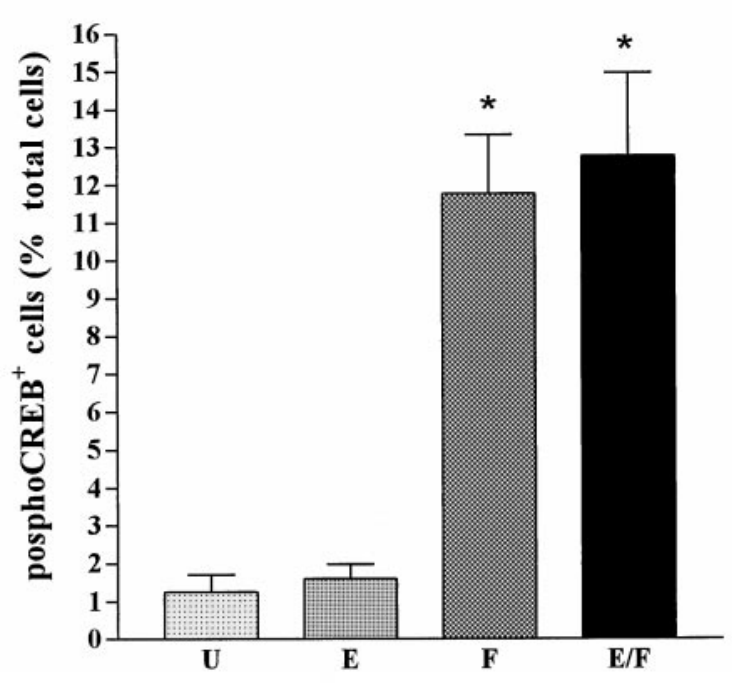

Figure 2. FGF-2-induced CREB phosphorylation in mouse E14 striatal cells cultured in vitro for $24 \mathrm{hr}$. $A$, Examples of phospho-CREB immunostaining (right panels) and corresponding phase-contrast pictures (left panels) of unstimulated cells (unst.) or after stimulation with the indicated growth factors. Arrows indicate phospho-CREB-immunopositive cells. Scale bar, $10 \mu \mathrm{m}$. $B$, Quantitative analysis of CREB phosphorylation in unstimulated cells $(U)$ and in cells stimulated with $\operatorname{EGF}(E), \operatorname{FGF}-2(F)$, or a combination of EGF and FGF-2 $(E / F)$. Data represent the means of five independent experiments. For each condition $>5000$ cells were counted. *Significantly different from unstimulated $(p<0.001)$.

\section{RESULTS}

\section{EGF and FGF-2 have distinct biological effects on cultures of mouse embryonic striatal cells}

Primary mouse E14 striatal precursor cells were grown in the presence of EGF and/or FGF-2 for 7 d, leading to the formation of neurospheres. The size and the number of neurospheres obtained were dependent on the growth factor added: EGF treatment gave rise to fewer and smaller neurospheres when compared with FGF-2 and EGF plus FGF-2 treatment (Fig. 1 $A-D$, Table 1). No neurospheres were found in control cultures grown in the absence of exogenous growth factor. Analysis of the total number of cells obtained from 7-d-old neurosphere cultures revealed the smallest cell number in EGF-treated cultures and an intermediate number with FGF-2, whereas EGF plus FGF-2 had a synergistic effect on growth and produced the highest number of cells (Fig. $1 E)$. We next determined the rate of BrdU incorporation in control and growth factor-treated cultures after 1,3 , and $6 \mathrm{~d}$ in vitro. One-day-old striatal cultures showed a similar rate of $\mathrm{BrdU}$ incorporation irrespective of the growth factor conditions (Fig. $1 F)$. After $3 \mathrm{~d}$ in vitro, cultures grown in the presence of FGF-2 and EGF plus FGF-2 contained significantly more dividing cells than EGF-treated and control cultures (Fig. $1 G$ ). After $6 \mathrm{~d}$ in vitro the same percentage of BrdU-labeled cells was found in all growth factor-treated cultures, whereas very few cells incorporated BrdU in control cultures (Fig. $1 H$ ). However, because cultures grown in EGF contained significantly less cells than those treated with FGF-2 and EGF plus FGF-2 (Fig. 1E), EGF treatment actually gave rise to approximately three to five times less BrdU-labeled cells than the other growth factor conditions. In addition, at each time point analyzed and in all growth factor conditions all the BrdU-immunopositive cells expressed nestin a marker for neuroepithelial precursors (data not shown).

Because these cultures represent a heterogeneous population of cells at different stages of neuronal and glial development, we next determined their phenotype immunocytochemically using antibodies to different marker proteins. These markers were nestin, TuJ1 (neurons), GFAP (astrocytes), and Gal-C (oligodendrocytes). Analysis of the cells $24 \mathrm{hr}$ after striatum dissection revealed that the majority of the cells were either nestin-positive $\left(\right.$ nestin $\left.{ }^{+}\right)$or $\mathrm{TuJ} 1$ positive $\left(\mathrm{TuJ} 1^{+}\right)$, whereas very few cells expressed GFAP or Gal-C (Table 2). In cultures grown for $7 \mathrm{~d}$ in the presence of either EGF or EGF plus FGF-2 and analyzed 24 $\mathrm{hr}$ after dissociation of the neurospheres and plating, the majority of cells were nestin ${ }^{+}$, whereas only a small percentage expressed $\mathrm{TuJ} 1$ (Table 2). The percentage of $\mathrm{TuJ} 1^{+}$cells in cultures grown for $7 \mathrm{~d}$ in FGF-2 was significantly higher than in cultures grown in either EGF or EGF plus FGF-2 (Table 2; $p<0.001$ ). However, when absolute numbers of $\mathrm{TuJ} 1^{+}$cells were compared, the difference was significant only between EGF and FGF-2 grown cultures. The glial cell content of 7-d-old cultures was small $(<1 \%$ of the cells were Gal-C-positive cells; no detectable GFAP staining) (Table 2). Approximately 25\% of the cells did not stain with any of the antibodies used irrespective of the growth factor treatment. Terminal deoxynucleotidyl transferase-mediated biotinylated UTP nick end-labeling staining indicated that these cells may have been undergoing apoptotic cell death (data not shown). Differentiation of the cells derived from 6- to 7-d-old cultures gave rise to a percentage of neurons and glial cells that did not vary with the growth factor conditions used during the first week in vitro (Table 2). These results demonstrate that nestin ${ }^{+}$precur- 

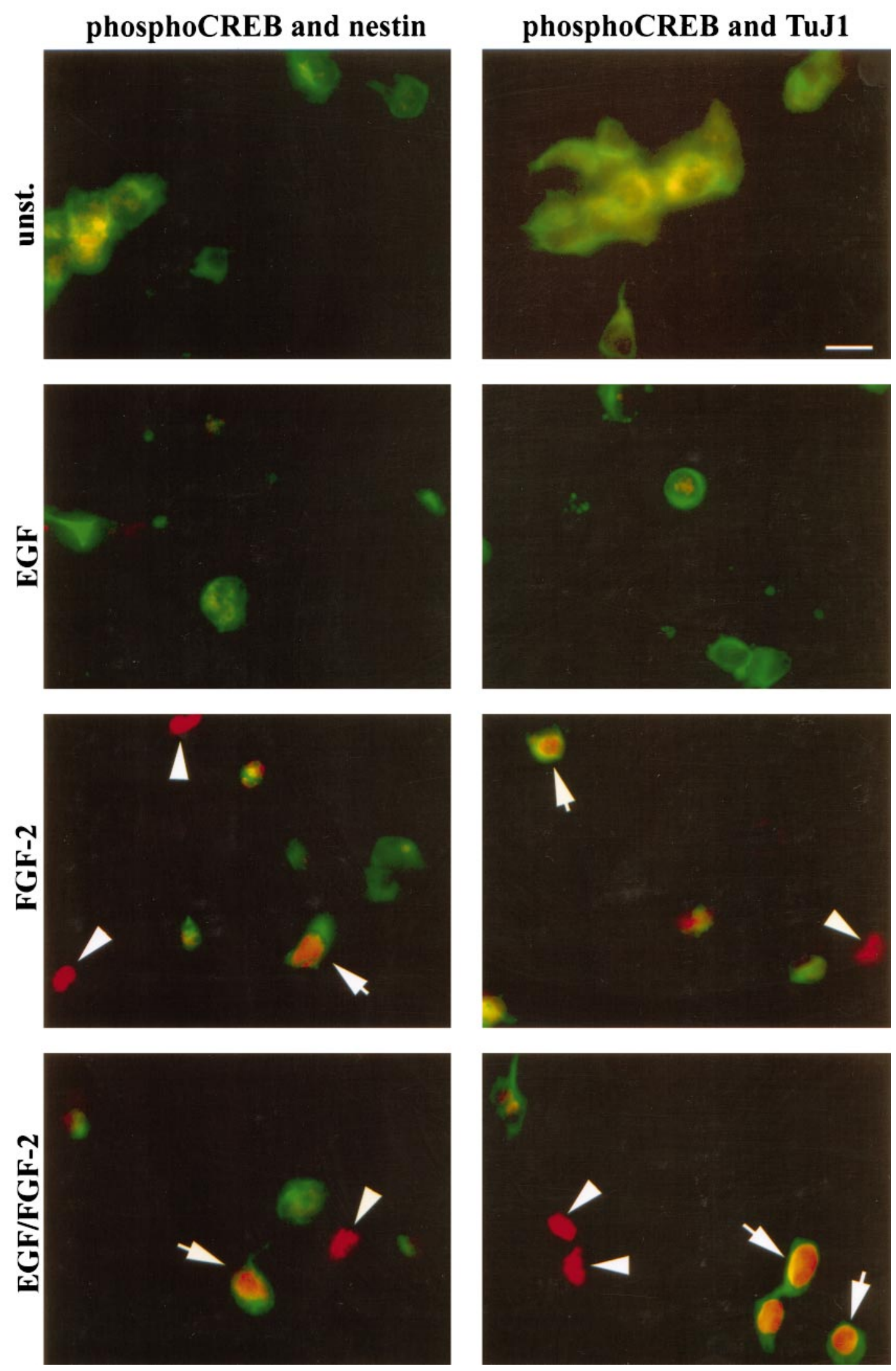

Figure 3. FGF-2-induced CREB phosphorylation in precursor cells and neurons present in mouse E14 striatal cells cultured in vitro for 24 hr. Examples of double immunostaining after stimulation of the cells with the indicated growth factors are shown. Phospho-CREB and nestin immunoreactivity (left panels) and phospho-CREB and TuJ1 immunoreactivity (right panels) are shown. Phospho-CREB immunoreactivity is viewed through rhodamine filters. Nestin and TuJ1 immunoreactivity is viewed through fluorescein filters. Arrows indicate double-immunopositive cells; arrowheads indicate cells immunopositive only for phospho-CREB; unst., unstimulated cells. Scale bar, $15 \mu \mathrm{m}$. 
A

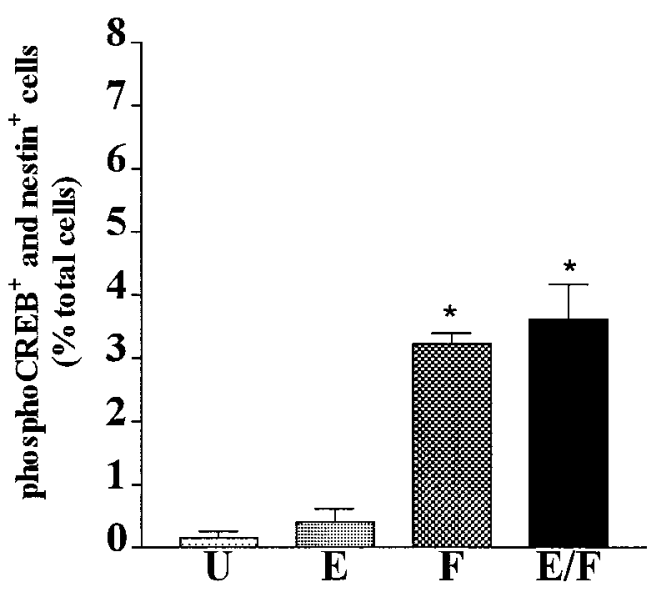

phosphoCREB and nestin

\author{
phosphoCREB and TuJ1
}

B

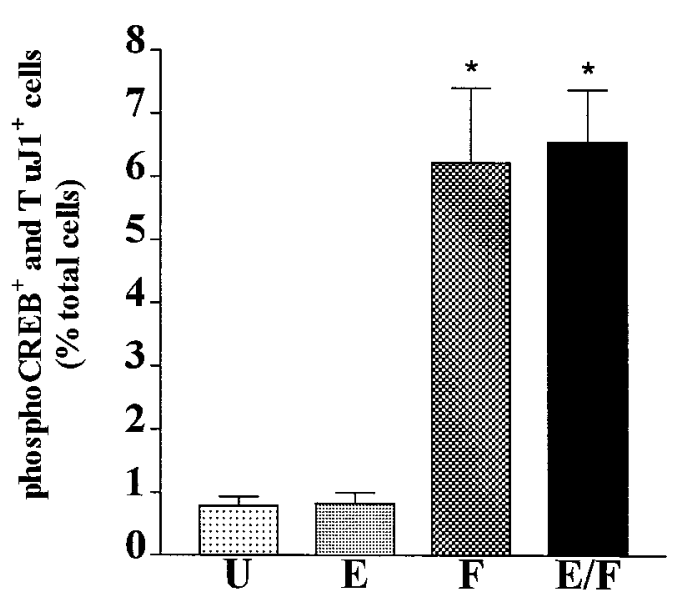

Figure 4. Characterization of FGF-2-responsive mouse E14 striatal cells cultured in vitro for $24 \mathrm{hr}$. Quantitative analysis of phospho-CREB and nestin $(A)$ or phospho-CREB and TuJ1 $(B)$ double-immunopositive cells in unstimulated cultures $(U)$ or in cultures stimulated with EGF $(E)$, FGF-2 $(F)$, or with a combination of both EGF and FGF-2 $(E / F)$. Data represent the means of four independent experiments. For each condition a total of 3000 cells were counted. *Significantly different from $U(p<0.001)$.

sor cells and $\mathrm{TuJ} 1^{+}$neurons are the two main cell types found in cultures of mouse E14 striatum grown for $7 \mathrm{~d}$ in EGF and/or FGF-2. These differences in proliferative responses, and in the relative abundance of precursor cells and neurons, indicate that EGF and FGF-2 have distinct biological effects on these cells. To investigate whether this reflects the existence of distinct subsets of cells differentially responding to either growth factor, we next analyzed EGF and FGF-2 responsiveness at the single-cell level.

\section{Striatal precursor cells respond to FGF-2 but not to EGF at early stages of in vitro development}

Binding of EGF and FGF-2 to their receptors activates the Ras/ERK signaling cascade culminating in the phosphorylation of the transcription factor CREB on serine 133 (Ginty et al., 1994; Xing et al., 1996). We used an antibody specific for CREB phosphorylated on serine 133 (Ginty et al., 1993) to identify individual cells responding to $\mathrm{EGF}\left(\mathrm{E}^{\text {res }}\right), \mathrm{FGF}-2\left(\mathrm{~F}^{\text {res }}\right)$, and both EGF and FGF-2 (E/F $\left.\mathrm{F}^{\text {res }}\right)$. Because CREB phosphorylation induced with growth factor stimulation was analyzed in cells grown attached to a substrate for $24 \mathrm{hr}$ in the absence of EGF and FGF-2, we first investigated whether this procedure affected proliferation or differentiation. We compared the growth factorinduced proliferative response in sister cultures exposed to the exogenous growth factors either immediately or $24 \mathrm{hr}$ after plating (for details see Materials and Methods). After $7 \mathrm{~d}$ of culturing no significant differences were found in either the total numbers of cells or the numbers of cell clusters formed in corresponding cultures (Table 3): EGF gave rise to the smallest, FGF-2 to intermediate, and EGF plus FGF-2 to the highest cell counts and numbers of clusters (Table 3), irrespective of the time of growth factor addition. In addition, growth factor starvation for $24 \mathrm{hr}$ did not change the expression of differentiation markers: the numbers of nestin ${ }^{+}$and $\mathrm{TuJ} 1^{+}$cells found $1 \mathrm{hr}$ after plating were virtually identical to those observed $24 \mathrm{hr}$ after plating (data not shown). These results show that the conditions used to analyze growth factor-induced CREB phosphorylation did not alter proliferation or differentiation of growth factor-responsive precursors.

We next analyzed CREB phosphorylation in mouse E14 striatal cells $24 \mathrm{hr}$ after dissection and plating in culture medium without EGF or FGF-2 (Fig. 2). Without stimulation with exogenous growth factors, only $1 \%$ of the cells showed nuclear phospho-CREB immunoreactivity. Compared with unstimulated cultures, addition of EGF did not increase the number of phospho-CREB-positive cells. In contrast, stimulation with FGF-2 or with a combination of EGF and FGF-2 induced CREB phosphorylation in $10-12 \%$ of the cells. These results indicate that mouse E14 striatal cells, cultured in vitro for $24 \mathrm{hr}$, contain $10-12 \% \mathrm{~F}^{\text {res }}$ cells, whereas no $\mathrm{E}^{\text {res }}$ cells appear to be present at this time. In control experiments cells were stimulated with $10 \mu \mathrm{M}$ forskolin, an activator of adenylate cyclase, which causes CREB phosphorylation in a receptor-independent manner by increasing intracellular levels of cAMP, leading to activation of cAMPdependent protein kinase (Gonzalez and Montminy, 1989). We found that virtually all cells were phospho-CREB-positive with forskolin treatment (data not shown).

We next characterized the phenotype of the $\mathrm{F}^{\text {res }}$ cells. Previous studies have shown that FGF-2 can act on differentiating neuronal cells (Ray and Gage, 1994; Bouvier and Mytilineou, 1995; Ghosh and Greenberg, 1995). To determine whether the $\mathrm{F}^{\text {res }}$ striatal cells were precursors or differentiating neurons, we performed double-immunostaining experiments using the phospho-CREBspecific antibody together with antibodies to either nestin or TuJ1. Examples of double-immunostaining experiments are shown in Figure 3; quantitative analysis of the data are illustrated in Figure 4 . We found that $75 \%$ of the $\mathrm{F}^{\text {res }}$ cells ( $8 \%$ of total cells) were $\mathrm{TuJ} 1^{+}$, whereas the remaining $\mathrm{F}^{\text {res }}$ cells $(3-5 \%$ of the total cells) were nestin ${ }^{+}$(Fig. $4 A, B$ ). These results identify two distinct populations of $\mathrm{F}^{\text {res }}$ cells in mouse E14 embryonic striatum: $\mathrm{TuJ}^{+}{ }^{+}$neurons and nestin ${ }^{+}$precursors. Neither of these cell types responded to EGF at this stage of in vitro development. 
A
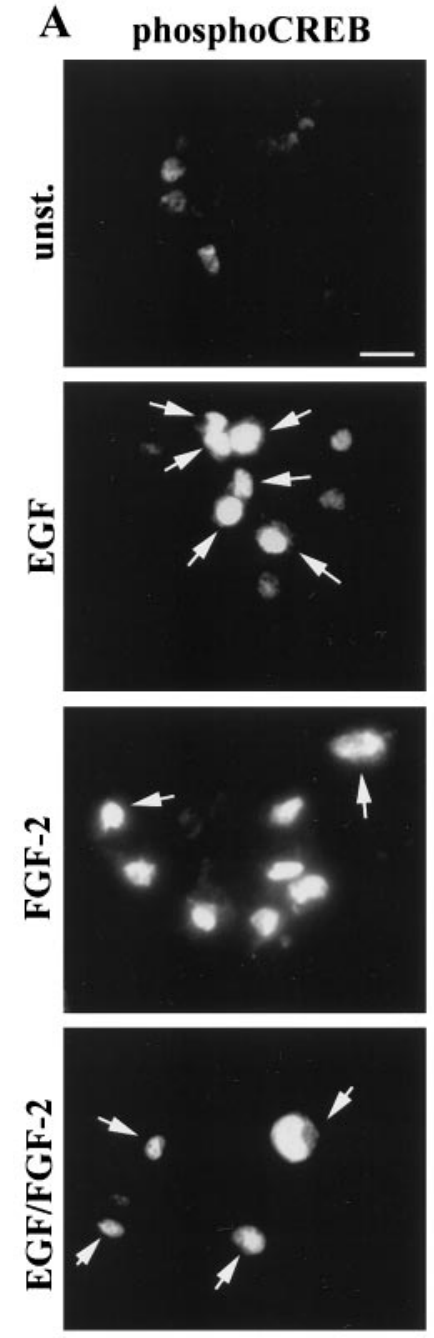
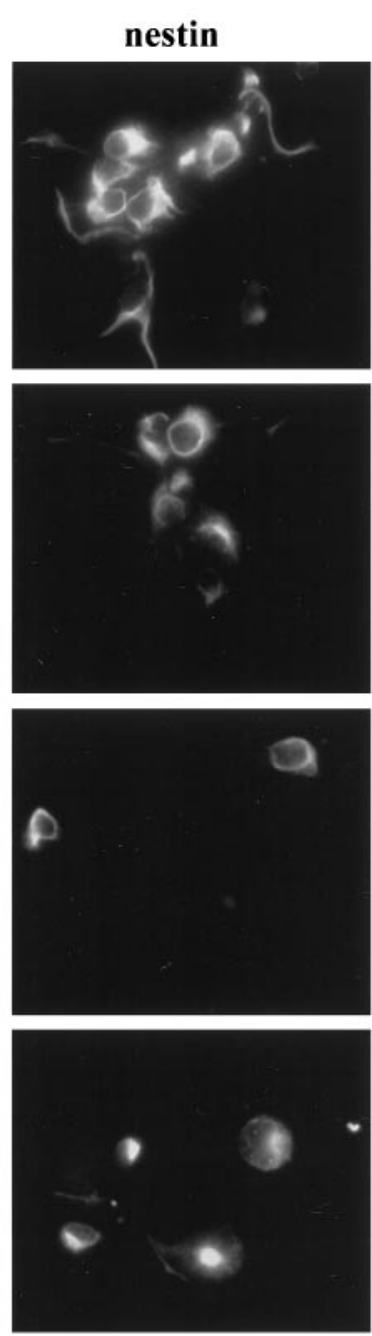

B
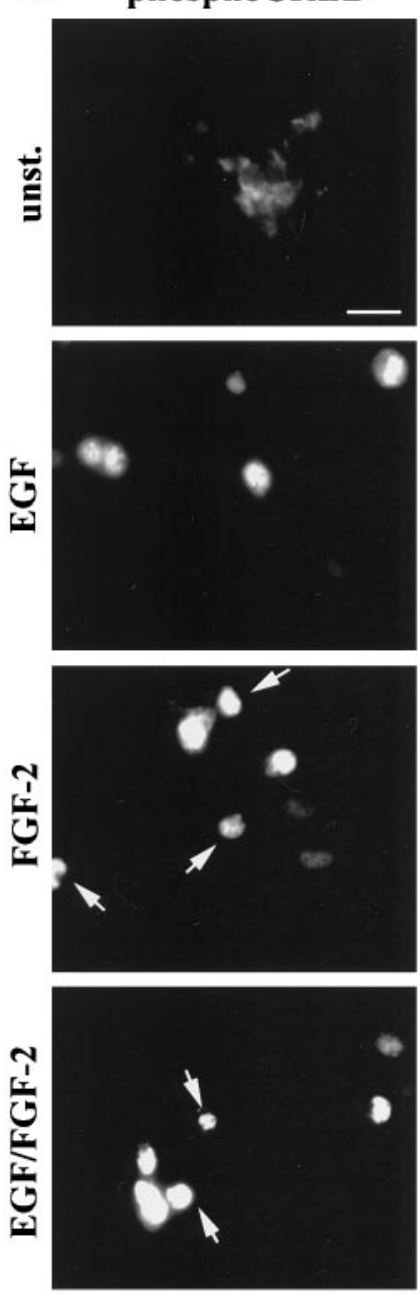

TuJ1
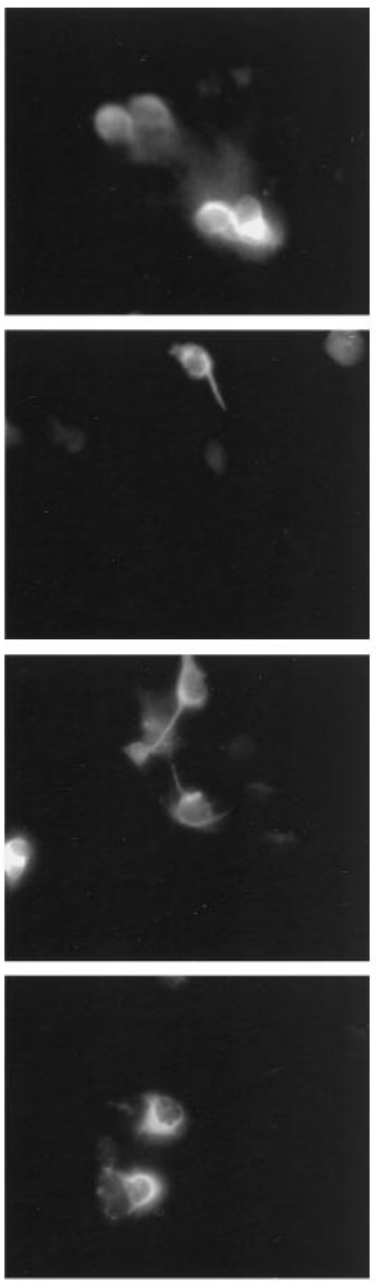

Figure 5. EGF- and FGF-2-induced CREB phosphorylation in precursor cells and neurons present in mouse E14 striatal cultures grown for $6 \mathrm{~d}$ in the presence of EGF plus FGF-2. A, B, Left panels, Examples of phospho-CREB immunostainings in unstimulated (unst.) cells and after stimulation with the indicated growth factors. Right panels, Nestin $(A)$ and TuJ1 $(B)$ immunoreactivity within the same visual fields. Arrows indicate doubleimmunopositive cells. Scale bar, $15 \mu \mathrm{m}$.

\section{Identification of single cells responding to both EGF and FGF-2 at later stages of in vitro development}

We next examined responsiveness to EGF and FGF-2 in cells isolated from mouse embryonic striatum and grown for $6 \mathrm{~d}$ in the presence of EGF and/or FGF-2. Figure 5 shows examples of double-immunostaining experiments; quantification of the data are shown in Figure 6. We found that, irrespective of the growth factor conditions during the expansion phase, both EGF and FGF-2 elicited a response in a similar percentage of nestin ${ }^{+}$cells (Figs. 5, 6), whereas the $\mathrm{TuJ} 1^{+}$cells responded to FGF-2 and not to EGF (Fig. 6B). To investigate whether EGF and FGF-2 acted on dividing cells, 6-d-old striatal cultures were labeled with BrdU in culture medium (without exogenous growth factors) for $24 \mathrm{hr}$ before growth factor stimulation. Analysis of cells immunopositive for both BrdU and phospho-CREB revealed that, irrespective of the growth factor condition during the $6 \mathrm{~d}$ in vitro, $>50 \%$ of the BrdU-positive cells (56 $\pm 7 \%, 57 \pm 6.6 \%$, and $63 \pm 7 \%$ in EGF, FGF-2, and EGF plus FGF-2 grown cultures, respectively) were also phospho-CREB-immunopositive after either EGF or FGF-2 stimulation (Fig. 7). These data underestimate the number of dividing growth factor-responsive cells: some cells, although proliferatively active, may be in a particular phase of the cell cycle during the $24 \mathrm{hr}$ starvation period that prevents them from incorporating BrdU.

To analyze whether EGF and FGF-2 stimulated the same or distinct subsets of nestin ${ }^{+}$cells, we next determined the number of phospho-CREB-positive cells after stimulation with a combination of EGF and FGF-2. We found that in cultures grown for $6 \mathrm{~d}$ with FGF-2 or EGF plus FGF-2, stimulation of the cells with either growth factor or with a combination of both induced a response in a similar number of nestin ${ }^{+}$cells (Fig. 6A). This indicates that EGF and FGF-2 act on the same cell population $\left(\mathrm{E} / \mathrm{F}^{\text {res }}\right.$ cells). In contrast, in EGF-grown cultures the number of cells stimulated with both EGF and FGF-2 was significantly greater than the number of cells responding to either growth factor alone (Fig. $6 A ; p<0.05$ ). This result suggests that, under these growth conditions, $\mathrm{E} / \mathrm{F}^{\text {res }}$ cells as well as $\mathrm{E}^{\text {res }}$ and $\mathrm{F}^{\text {res }}$ cells are present in the cultures. Given the difference in total cell counts obtained after $7 \mathrm{~d}$ after each growth factor treatment (Fig. $1 B$ ), the absolute number of $\mathrm{E} / \mathrm{F}^{\text {res }}$ cells was three to seven times 
A

6 DIV EGF

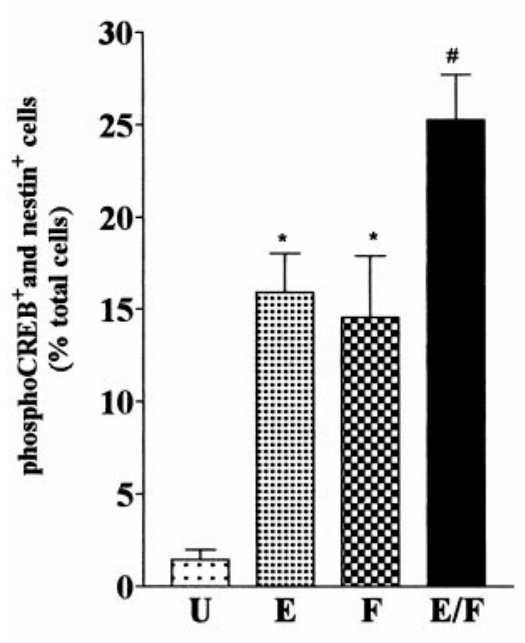

B

6 DIV EGF

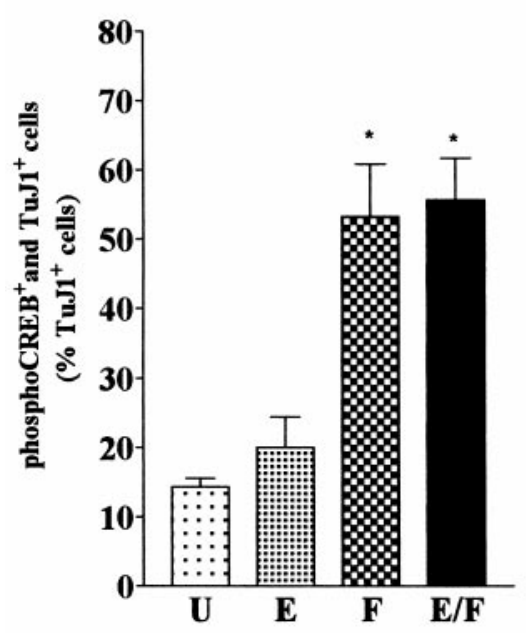

6 DIV FGF-2

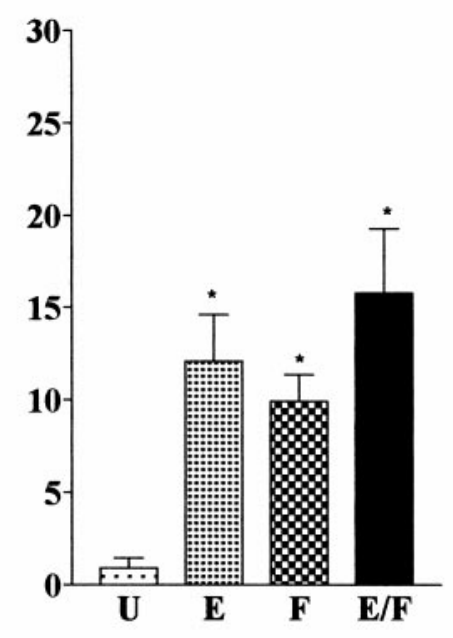

6 DIV FGF-2

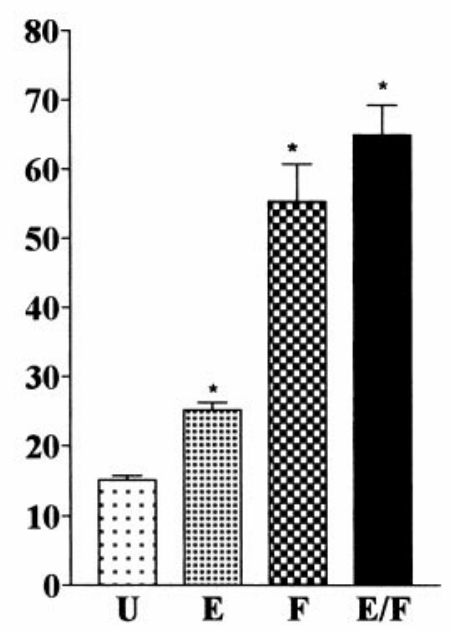

6 DIV EGF+FGF-2

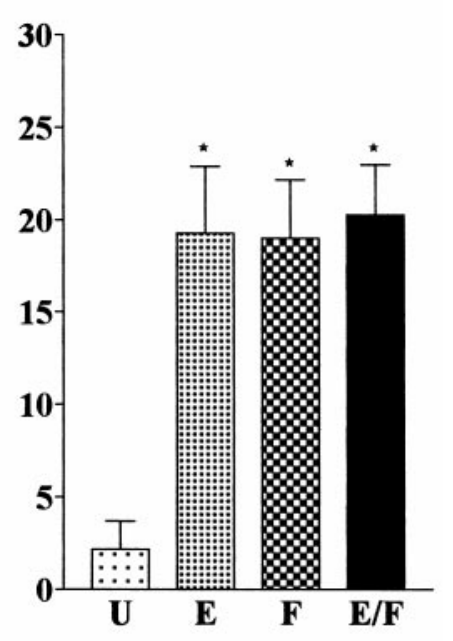

6 DIV EGF+FGF-2

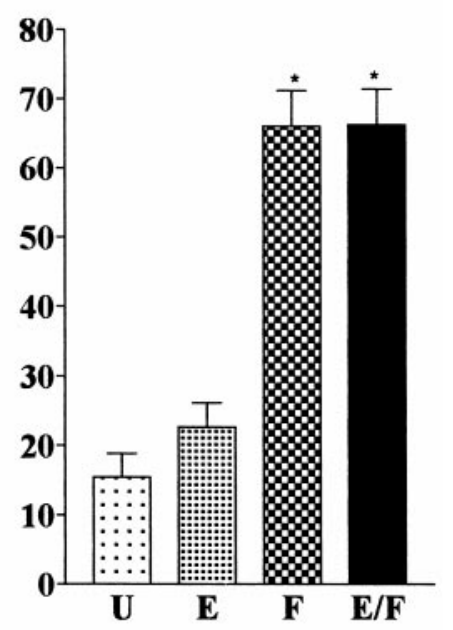

Figure 6. Characterization of growth factor-responsive cells in cultures of striatal precursor cells grown for $6 \mathrm{~d}$ in the presence of EGF (6 DIV EGF) and FGF-2 (6DIV FGF-2) or in the presence of both $(6 D I V E G F+F G F-2)$. Quantitative analysis of the double-immunopositive cells $(A$, phospho-CREB and nestin; $B$, phospho-CREB and TuJ1) in unstimulated cultures $(U)$ and in cultures stimulated with EGF $(E)$, FGF-2 $(F)$, or a combination of EGF and FGF-2 $(E / F)$. Data represent the means of three independent experiments. For each condition $>1000$ cells were counted. $A$, *Significantly different from $U(p<0.01)$; ${ }^{\#}$ Significantly different from $E$ and $F(p<0.05)$ and from $U(p<0.001)$. B, *Significantly different from unst. $(p<0.001)$. The differences in the numbers of TuJ1 and phospho-CREB double-immunopositive cells in $U$ and $E$ are not significant.

smaller in EGF-grown cultures than in cultures grown in the presence of FGF-2. We next investigated the role of FGF-2 in the generation of $\mathrm{E} / \mathrm{F}^{\text {res }}$ cells.

\section{Priming of neural precursor cells with FGF-2 induces the appearance of a cell population responding to both EGF and FGF-2 after $2 \mathrm{~d}$ in vitro}

Exogenous FGF-2 could increase the number of $\mathrm{E} / \mathrm{F}^{\text {res }}$ cells by promoting the division of $\mathrm{F}^{\text {res }}$ precursor cells that will subsequently acquire EGF responsiveness in an FGF-2-independent manner. Alternatively, FGF-2 may, in addition to inducing proliferation, promote the transition of growth factor responsiveness from $\mathrm{F}^{\mathrm{res}}$ to $\mathrm{E} / \mathrm{F}^{\mathrm{res}}$. To distinguish between these two possibili- ties, mouse E14 striatal cells were primed for $24 \mathrm{hr}$ with either EGF or FGF-2 after striatum dissection. Cells were then plated onto poly-L-lysine-laminin-coated chamber slides and analyzed for EGF and FGF-2 responsiveness after an additional $24 \mathrm{hr}$ in vitro in the absence of exogenous growth factors. In FGF-2primed cultures, the same percentage of nestin ${ }^{+}$cells, representing $\sim 5 \%$ of the total number of cells, showed phospho-CREB nuclear immunostaining after stimulation with either EGF or FGF-2 alone or with a combination of both (Fig. $8 B$ ), demonstrating that EGF and FGF-2 stimulated the same precursor cells (E/ $\mathrm{F}^{\text {res }}$ cells). $\mathrm{F}^{\text {res }}$ cells, which were present at $24 \mathrm{hr}$ after dissection, were no longer detected (Fig. $8 \mathrm{~B}$; for a comparison, also 

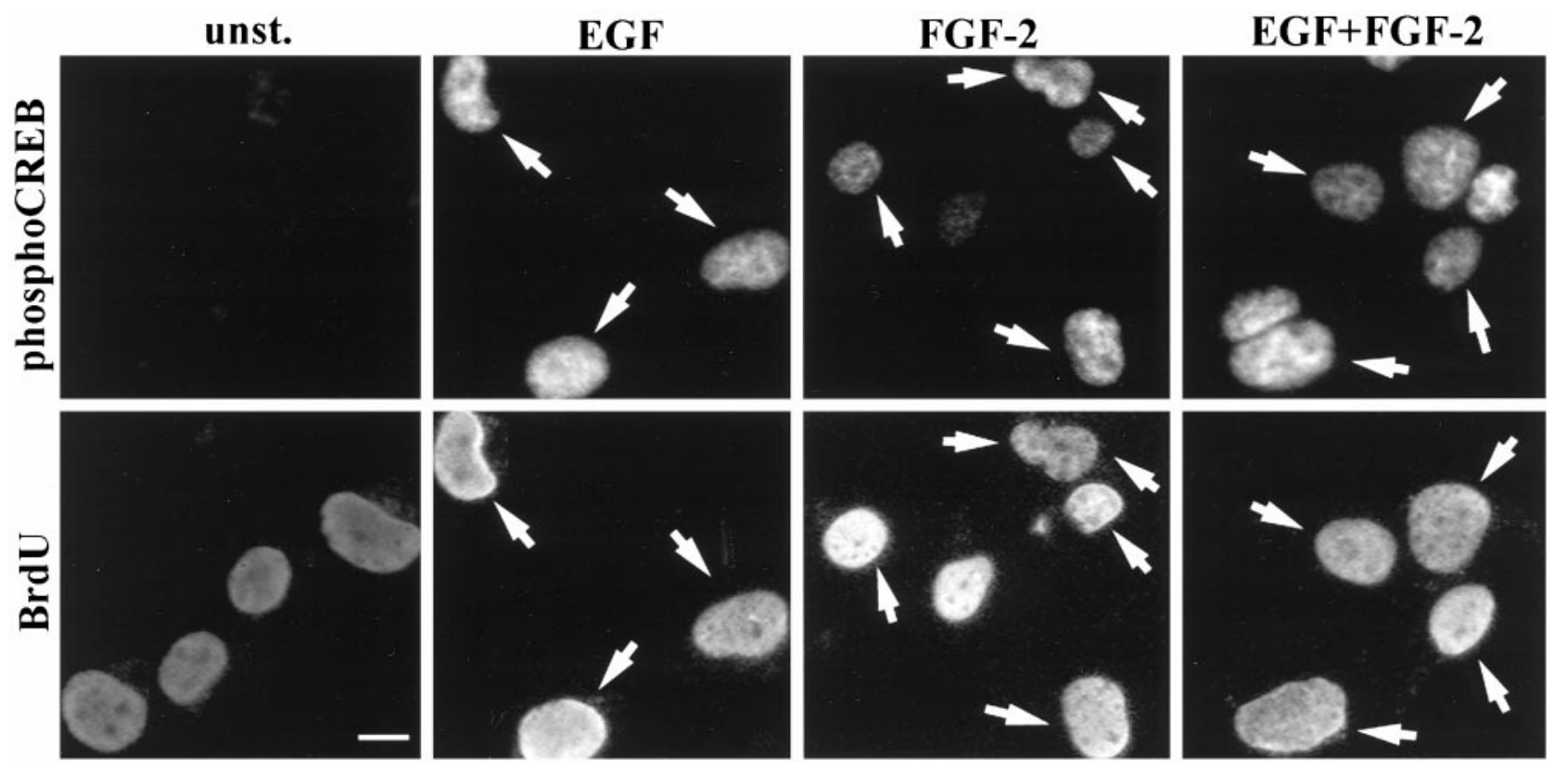

Figure 7. BrdU and phopho-CREB double immunostaining. Examples of phospho-CREB immunostainings in unstimulated cultures (unst.) and after stimulation with the indicated growth factors (top panels) and BrdU-immunopositive precursors within the same visual fields (bottom panels). Arrows indicate double-immunopositive cells. Scale bar, $5 \mu \mathrm{m}$.

see Fig. $4 A$ ), indicating that they had acquired EGF responsiveness after FGF-2 treatment. In contrast, this transition in growth factor responsiveness, from $\mathrm{F}^{\text {res }}$ to $\mathrm{E} / \mathrm{F}^{\text {res }}$, was not observed in EGF-primed cultures, which, similar to $24 \mathrm{hr}$ after dissection, contained cells responding to FGF-2 but not to EGF (i.e., $\mathrm{F}^{\text {res }}$ cells) (Fig. 8A). Priming with either EGF or FGF-2 did not affect the $\mathrm{TuJ} 1{ }^{+}$cells, which remained responsive to FGF-2 only (Fig. $8 C, D$; for a comparison, also see Fig. $4 B$ ). These results demonstrate acquisition of growth factor responsiveness on single neural precursors: cells initially responding to FGF-2 only acquire EGF responsiveness at later stages of in vitro development. FGF-2 but not EGF can promote this transition.

\section{DISCUSSION}

Phospho-CREB-specific antibodies: a tool for characterization of growth factor-responsive cells in heterogeneous populations of neural precursor cells

Previous studies have used clonal analysis to show that single neural precursors divide in response to EGF or FGF-2 and subsequently differentiate into multiple neural phenotypes (Kilpatrick and Bartlett, 1993; Gage et al., 1995; Qian et al., 1997). However, clonal analysis cannot detect the response of single cells to growth factor signals. In this study we used a novel approach to characterize, at the single-cell level, EGF- and FGF-2-responsive cells in cultures of mouse E14 striatum. Phosphorylation of CREB on serine 133 is one of the intracellular events following activation of receptor tyrosine kinases (Ginty et al., 1994; Xing et al., 1996). Using an antibody recognizing this phosphorylated form of CREB, we identified EGF- and FGF-2-responsive cells by immunostaining. This antibody also recognizes the phosphorylated form of the transcription factor ATF1, which is closely related to CREB. This cross-reactivity, however, does not represent a limit for our experimental approach, because the antibody was used as an activation marker. Alternative methods, such as RT-PCR and immunocytochemistry, have been used previously to detect growth factor receptor expression in neural precursors at the level of mRNA (both EGF and FGF receptors) and protein (FGF receptor only) (Reynolds et al., 1992; Vescovi et al., 1993; Qian et al., 1997). However, it has been difficult to assess growth factor receptor expression in individual cells, which may be because of their low abundance and/or lack of suitable antibodies. Analysis of CREB phosphorylation, rather than immunodetection of growth factor receptor molecules, has several advantages. It provides a detection method to analyze the response to different growth factors acting on receptor tyrosine kinases. It is a very sensitive method because CREB phosphorylation is the result of a cascade of intracellular biochemical events in which the initial signal is amplified. Therefore, it allows identification of cells expressing very few growth factor receptors that would be difficult to detect by conventional immunocytochemical staining. A potential drawback of this approach is that cells responding to growth factors without activating the classical Ras/ERK pathway leading to CREB phosphorylation will remain undetected. However, all available evidence suggests that activation of receptor tyrosine kinases, in particular that of EGF and FGF-2 receptors, is linked to Ras/ERK signaling cascades (Marshall, 1995). Cells that do not express CREB would also remain undetected with this assay for growth factor responsiveness. However, CREB is widely expressed in the CNS (Herdegen et al., 1997), and immunostaining of the cells analyzed in this study shows that virtually all cells express CREB protein (data not shown).

\section{EGF responsiveness arises later during in vitro development}

The majority of the cells in primary striatal cultures were either nestin ${ }^{+}$or $\mathrm{TuJ}^{+}$at any given time analyzed in this study. Nestin has been widely accepted as a marker of neuroepithelial precursor cells (Lendahl et al., 1990), and TuJ1 has been recognized as a neuronal marker (Menezes and Luskin, 1994), although low levels of TuJ1 can be found also in immature oligodendrocyte. We found that $\mathrm{TuJ} 1{ }^{+}$cells responded to FGF-2, irrespective of the growth conditions and the length of in vitro culturing. This is 

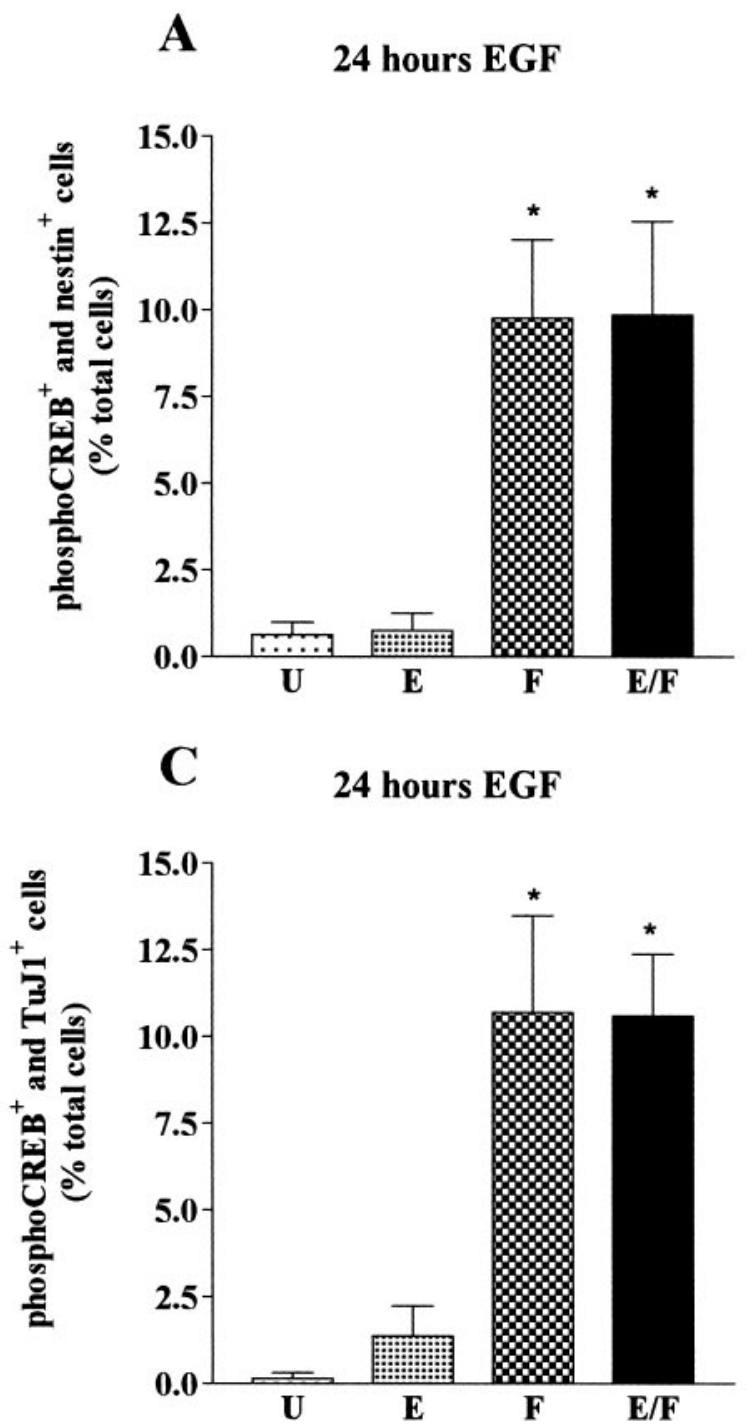

B

\section{4 hours FGF-2}

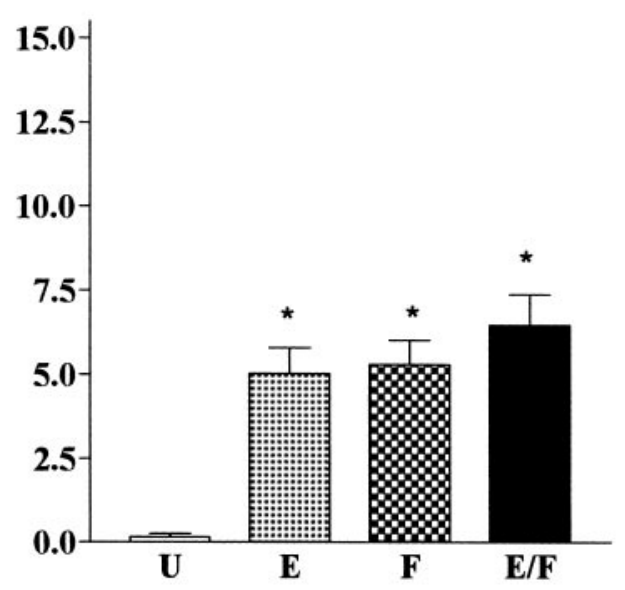

D

\section{4 hours FGF-2}

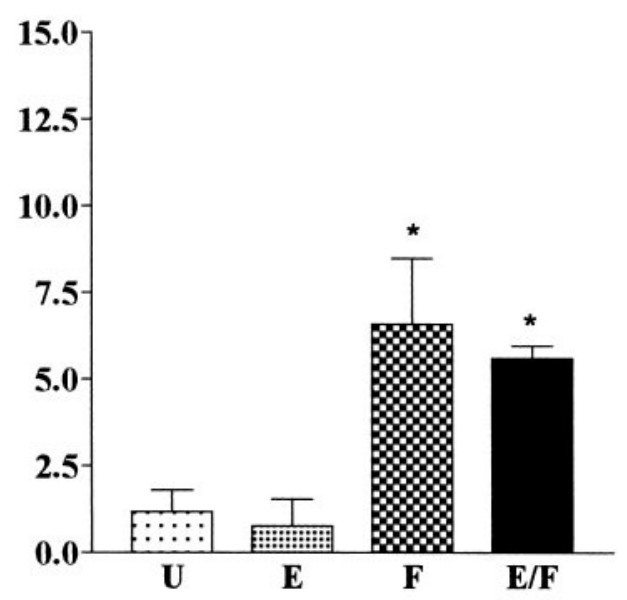

Figure 8. Characterization of growth factor-responsive cells in cultures of striatal precursor cells primed for $24 \mathrm{hr}$ with EGF ( $A, C)$ or FGF-2 (B, $D)$. Graphical representation of the percentage of double-immunopositive phospho-CREB and nestin $(A, B)$ and phospho-CREB and TuJ1, $(C, D)$ cells in unstimulated cultures $(U)$ and in cultures stimulated with EGF $(E)$, FGF-2 $(F)$, or a combination of EGF and FGF-2 $(E / F)$. Data represent the means of three independent experiments. For each condition a total of 600 cells were counted. $A, B,{ }^{*}$ Significantly different from $U(p<0.01)$. $C$, $D$, *Significantly different from $U(p<0.001)$.

consistent with the previous observation that rat embryonic cortical neurons respond to FGF-2 but not EGF (Ghosh and Greenberg, 1995). In contrast, growth factor responsiveness of the nestin $^{+}$cells changes during in vitro development. After $1 \mathrm{~d}$ in vitro, E14 striatal cultures contain nestin ${ }^{+}$cells responding to FGF-2, whereas EGF-responsive cells are undetectable. This provides a possible explanation for the previous observation that precursors derived from rodent embryonic striatum proliferate in response to EGF only after 4-5 d in vitro (Reynolds et al., 1992; Svendsen et al., 1995). Our results indicate that this lack of EGF-induced proliferation is attributable to the absence of EGFresponsive cells rather than to the inability of the cells to divide at early stages of in vitro development. After $7 \mathrm{~d}$ in vitro a population of cells had acquired EGF responsiveness and was stimulated by both EGF and FGF-2 (E/F ${ }^{\text {res }}$ cells). These cells represented the majority, if not all, of the dividing cells in 7-d-old cultures. The change in growth factor responsiveness occurred under all culture conditions; however, FGF-2 and EGF plus
FGF-2-treated cultures contained three and seven times, respectively, more $\mathrm{E} / \mathrm{F}^{\mathrm{res}}$ cells than EGF-grown cultures. This difference in $\mathrm{E} / \mathrm{F}^{\mathrm{res}}$ cell number correlates with the total cell counts and the number and size of neurospheres after $7 \mathrm{~d}$ in vitro. There is also a close correlation between the time of appearance of the $\mathrm{E} / \mathrm{F}^{\mathrm{res}}$ cells and the increase in the rate of BrdU incorporation. This suggests that the $\mathrm{E} / \mathrm{F}^{\mathrm{res}}$ cells are critical for neurosphere formation. It is possible that the $\mathrm{E} / \mathrm{F}^{\text {res }}$ cells, which constitute $15-20 \%$ of the cell population, represent the fraction $(18.7 \%)$ of cells derived from primary neurospheres that was previously found to generate secondary neurospheres in response to EGF (Reynolds and Weiss, 1996).

Although the differentiation potential of the $\mathrm{E} / \mathrm{F}^{\text {res }}$ cells remains to be investigated directly, several lines of evidence suggest that $\mathrm{E} / \mathrm{F}^{\text {res }}$ cells represent multipotent precursors. First, EGF and FGF-2 support the proliferation of striatal multipotent neural precursors, and $\mathrm{E} / \mathrm{F}^{\mathrm{res}}$ cells are the principal population of growth factor-responsive precursors found under all growth con- 


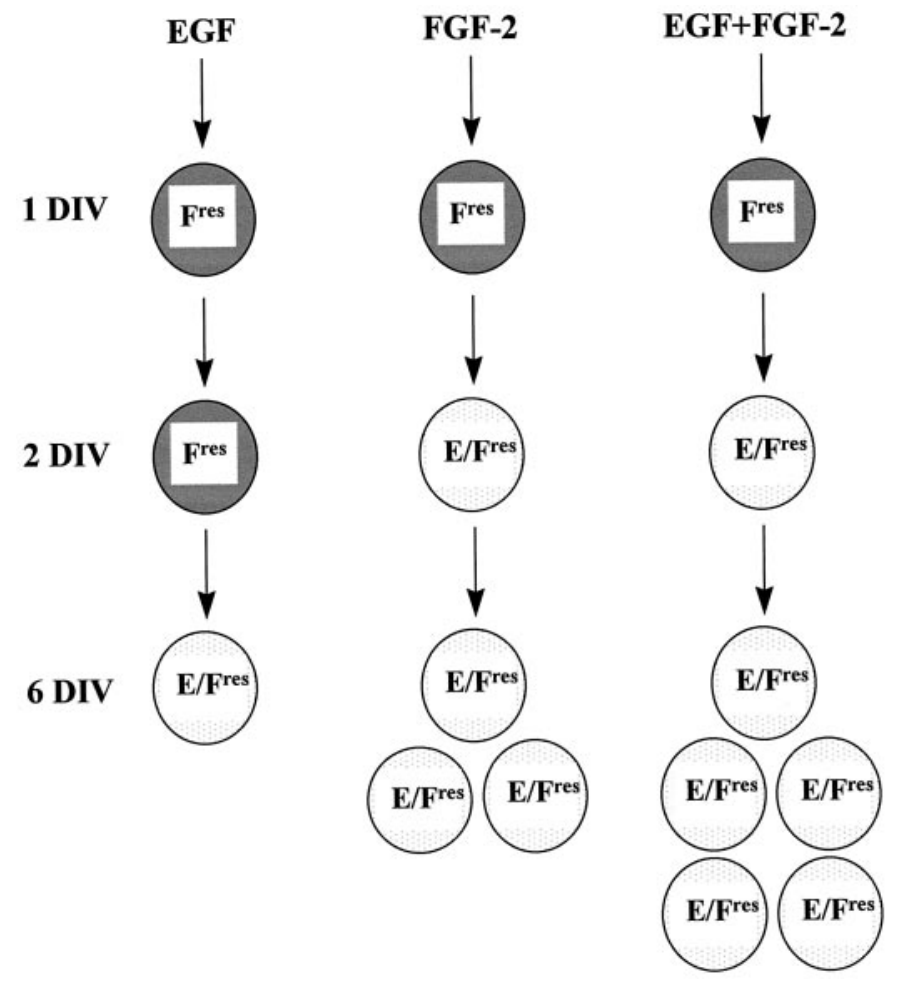

Figure 9. Model illustrating the generation of neural precursors responding to both EGF and FGF-2 during in vitro development. Neural precursors responding to FGF-2 $\left(\mathrm{F}^{\mathrm{res}}\right)$ after $1 \mathrm{~d}$ in vitro $(D I V)$ acquire EGF responsiveness later during in vitro development, giving rise to precursors responding to both growth factors $\left(\mathrm{E} / \mathrm{F}^{\text {res }}\right)$. The effects of the different growth factor conditions on this transition are illustrated: FGF-2, but not EGF, promotes the change in growth factor responsiveness; EGF plus FGF-2 has a synergistic effect on the growth of $\mathrm{E} / \mathrm{F}^{\text {res }}$ cells. The numbers of $\mathrm{E} / \mathrm{F}^{\text {res }}$ cells indicate their approximate growth rate under the different culture conditions.

ditions analyzed. Second, the relative abundance of $\mathrm{E} / \mathrm{F}^{\mathrm{res}}$ cells present in neurospheres correlates with the percentage of neurons and glial cells obtained after differentiation.

In EGF-treated cultures, two other cell populations are present: $\mathrm{E}^{\text {res }}$ cells and $\mathrm{F}^{\text {res }}$ cells. The $\mathrm{F}^{\text {res }}$ cells could be similar to those found after $24 \mathrm{hr}$ in vitro that have not yet acquired EGF responsiveness. The nature of the $\mathrm{E}^{\text {res }}$ cells is less clear. Because EGF receptor mRNA is expressed in many differentiating cell populations of the embryonic brain (Kornblum et al., 1997), one possible explanation for the presence of $E^{\text {res }}$ cells in EGF- but not FGF-2-grown cultures is that they may represent more lineagerestricted progenitors with a limited or slow proliferative activity. Therefore, these cells could be overgrown by more rapidly dividing cells present in FGF-2-containing cultures. Alternatively, the $\mathrm{E}^{\mathrm{res}}$ cells may originate from $\mathrm{F}^{\mathrm{res}}$ cells that only temporarily acquired responsiveness to both growth factors (i.e., $\mathrm{E} / \mathrm{F}^{\text {res }}$ cells) but have lost FGF-2 responsiveness in the absence of FGF-2 in the culture medium.

\section{FGF-2 promotes acquisition of EGF responsiveness during neural precursor development}

Our priming experiments indicate that FGF-2 promotes the appearance of an EGF response in cells originally responding to FGF-2 only. A short (24 hr) exposure to FGF-2 induced the appearance of $\mathrm{E} / \mathrm{F}^{\text {res }}$ cells after $2 \mathrm{~d}$, whereas $\mathrm{F}^{\text {res }}$ nestin ${ }^{+}$cells were no longer detected. EGF was unable to promote this tran- sition in growth factor responsiveness, which may explain why the number of $\mathrm{E} / \mathrm{F}^{\text {res }}$ cells after $7 \mathrm{~d}$ in vitro was lower in EGF-grown cultures than in cultures exposed to FGF-2. The here-described role for FGF-2 in promoting a change in growth factor responsiveness resembles a previous observation by Cattaneo and McKay (1990), who found that rat embryonic precursors proliferated in response to nerve growth factor (NGF) after a $2 \mathrm{~d}$ exposure to FGF-2, whereas untreated cultures did not respond to NGF.

Exogenous FGF-2 is not essential for the acquisition of EGF responsiveness in striatal cells, because $\mathrm{E} / \mathrm{F}^{\text {res }}$ cells were also identified in EGF-grown cultures, although in small numbers. Although this could indicate that the acquisition of EGF responsiveness is a default pathway during in vitro development, the finding that the neural precursor cultures derived from embryonic cerebrum may secrete FGF-2 suggests that endogenous FGF-2, or a related molecule, may be responsible for changing growth factor responsiveness (Kilpatrick and Bartlett, 1995). This hypothesis is supported by the observation that EGF is virtually ineffective in inducing proliferation of primary striatal cells grown at clonal density (Reynolds and Weiss, 1996). Under these conditions secreted FGF-2, or a similarly acting growth factor, may not reach a concentration high enough to be biologically effective.

One possible function of this FGF-2-induced change in growth factor responsiveness could be that it allows the cells to proliferate more actively. Indeed, we found that EGF plus FGF-2 had a synergistic effect, compared with EGF or FGF-2 alone, on total cell counts and on the number and size of neurospheres, which is consistent with previous observations (Weiss et al., 1996a; Svendsen et al., 1997). The acquisition of EGF responsiveness could also affect neural cell differentiation. For example, the appearance of EGF responsiveness in cultures of mouse E17 cerebrum coincides with the appearance of glial-restricted precursors. These precursors are absent in similar cultures from E10 cerebrum, which appear to lack EGF responsiveness (Kilpatrick and Bartlett, 1995). Other studies have shown that overexpression of EGF receptor alters the differentiation characteristics of rat retinal precursors and of cortical progenitors of the ventricular zone (Lillien, 1995; Burrows et al., 1997).

The mechanism through which FGF-2 induces EGF responsiveness could be the result of induction of EGF receptor mRNA and protein. The promoter of the EGF receptor gene contains several putative regulatory elements that function either as repressors or activators of transcription (Hou et al., 1994; Johnson, 1996). Whether FGF-2 stimulates a transcriptional activator, inhibits a repressor, or alternatively, induces an EGF response by a post-transcriptional mechanism remains to be investigated.

\section{Conclusions}

Neural precursor cells initially responding to FGF-2 only become responsive to EGF later during in vitro development. This change in growth factor responsiveness is promoted by FGF-2 and leads to the appearance of a population of precursor cells responding to both EGF and FGF-2. A model illustrating our findings is shown in Figure 9.

\section{REFERENCES}

Bouvier MM, Mytilineou C (1995) Basic fibroblast growth factor increases division and delays differentiation of dopamine precursors in vitro. J Neurosci 15:7141-7149.

Burrows RC, Wancio D, Levitt P, Lillien L (1997) Response diversity and the timing of progenitors cell maturation are regulated by devel- 
opmental changes in EGFR expression in the cortex. Neuron 19:251-267.

Cattaneo E, McKay R (1990) Proliferation and differentiation of neuronal stem cells regulated by nerve growth factor. Nature 347:762-765.

Cattaneo E, McKay R (1991) Identifying and manipulating neuronal stem cells. Trends Neurosci 14:338-340.

Gage FH, Ray J, Fisher LJ (1995) Isolation, characterisation, and use of stem cells from the CNS. In: Annual Review of Neuroscience (Cowan WM, Shooter EM, Stevens CF, Thompson RF, eds), pp 159-192. Palo Alto, CA: Annual Reviews.

Gensburger C, Labourdette G, Sensenbrenner M (1987) Brain basic fibroblast growth factor stimulates the proliferation of rat neuronal precursor cells in vitro. FEBS Lett 217:1-5.

Ghosh A, Greenberg ME (1995) Distinct roles for bFGF and NT-3 in the regulation of cortical neurogenesis. Neuron 15:89-103.

Ginty DD, Kornhauser JM, Thompson MA, Bading H, Mayo KE, Takahashi JS, Greenberg ME (1993) Regulation of CREB phosphorylation in the suprachiasmatic nucleus by light and a circadian clock. Science 260:238-241.

Ginty DD, Bonni A, Greenberg ME (1994) Nerve growth factor activates a Ras-dependent protein kinase that stimulates $c$-fos transcription via phosphorylation of CREB. Cell 77:713-725.

Gonzalez GA, Montminy MR (1989) Cyclic AMP stimulates somatostatin gene transcription by phosphorylation of CREB at serine 133. Cell 59:675-680.

Gritti A, Parati EA, Cova L, Frolichsthal P, Galli R, Wanke E, Faravelli L, Morassutti DJ, Roisen F, Nickel DD, Vescovi AL (1996) Multipotential stem cells from the adult mouse brain proliferate and self-renew in response to basic fibroblast growth factor. J Neurosci 16:1091-1100.

Herdegen T, Blume A, Buschmann T, Georgakopoulos E, Winter C, Schmid W, Hsieh TF, Zimmermann M, Gass P (1997) Expression of activating transcription factor-2, serum response factor and $\mathrm{cAMP} / \mathrm{Ca}$ response element binding protein in the adult rat brain following generalized seizures, nerve fibre lesions and ultraviolet irradiation. Neuroscience 81:199-212.

Hou X, Johnson AC, Rosner MR (1994) Identification of an epidermal growth factor receptor transcriptional repressor. J Biol Chem 269:4307-4312.

Johe KK, Hazel TG, Muller T, Dugich-Djordjevic MM, McKay RDG (1996) Single factors direct the differentiation of stem cells from the fetal and adult central nervous system. Genes Dev 10:3129-3140.

Johnson AC (1996) Activation of epidermal growth factor receptor gene transcription by phorbol 12-myristate 13 -acetate is mediated by activator protein 2. J Biol Chem 271:3033-3038.

Kilpatrick TJ, Bartlett PF (1993) Cloning and growth of multipotential neural precursors: requirements for proliferation and differentiation. Neuron 10:255-265.

Kilpatrick TJ, Bartlett PF (1995) Cloned multipotential precursors from the mouse cerebrum require FGF-2, whereas glial restricted precursors are stimulated with either FGF-2 or EGF. J Neurosci 15:3653-3661.

Kilpatrick TJ, Richards LJ, Bartlett PF (1995) The regulation of neural precursor cells within the mammalian brain. Mol Cell Neurosci 6:2-15. Kornblum HI, Hussain RJ, Bronstein JM, Gall CM, Lee DC, Seroogy KB (1997) Prenatal ontogeny of the epidermal growth factor receptor and its ligand, transforming growth factor alpha, in the rat brain. J Comp Neurol 380:243-261.

Lendahl U, Zimmerman LB, McKay RDG (1990) CNS stem cells express a new class of intermediate filament protein. Cell 60:585-595.
Lillien L (1995) Changes in retinal cell fate induced by overexpression of EGF receptor. Nature 377:158-162.

Lindvall O (1997) Neural transplantation hope for patients with Parkinson's disease. NeuroReport 8:3-10.

Marshall CJ (1995) Specificity of receptor tyrosine kinase signaling: transient versus sustained extracellular signal-regulated kinase activation. Cell 80:179-185.

McKay R (1997) Stem cells in the central nervous system. Science 276:66-71.

Menezes JRL, Luskin MB (1994) Expression of neuron-specific tubulin defines a novel population in the proliferative layers of the developing telencephalon. J Neurosci 14:5399-5416.

Qian X, Davis AA, Goderie SK, Temple S (1997) FGF-2 concentration regulates the generation of neurons and glia from multipotent cortical stem cells. Neuron 18:81-93.

Ray J, Gage FH (1994) Spinal cord neuroblasts proliferate in response to basic fibroblast growth factor. J Neurosci 14:3548-3564.

Ray J, Peterson DA, Schinstine M, Gage FH (1993) Proliferation, differentiation, and long-term culture of primary hippocampal neurons. Proc Natl Acad Sci USA 90:3602-3606.

Reynolds BA, Weiss S (1992) Generation of neurons and astrocytes from isolated cells of the adult mammalian central nervous system. Science 255:1707-1710.

Reynolds BA, Weiss S (1996) Clonal and population analyses demonstrate that an EGF-responsive mammalian embryonic CNS precursor is a stem cell. Dev Biol 175:1-13.

Reynolds BA, Tetzlaff W, Weiss S (1992) A multipotent EGFresponsive striatal embryonic progenitor cell produces neurons and astrocytes. J Neurosci 12:4565-4574.

Shihabuddin LS, Ray J, Gage FH (1997) FGF-2 is sufficient to isolate progenitors found in the adult mammalian spinal cord. Exp Neurol 148:577-586.

Svendsen CN (1997) Neural stem cells for brain repair. Alzheimer Res. 3:131-135.

Svendsen CN, Fawcett J, Bentlage C, Dunnett SB (1995) Increased survival of rat EGF-generated CNS progenitor cells using B27 supplemented medium. Exp Brain Res 102:407-414.

Svendsen C, Skepper JN, Rosser AE, ter Borg M, Tyers P, Ryken T (1997) Restricted growth potential of rat striatal precursors as compared to mouse. Brain Res Dev Brain Res 99:253-258.

Temple S, Davis AD (1994) Isolated rat cortical progenitor cells are maintained in division in vitro by membrane-associated factors. Development 120:999-1008.

Vescovi AL, Reynolds BA, Fraser DD, Weiss S (1993) bFGF regulates the proliferative fate of unipotent (neuronal) and bipotent (neuronal/ astroglial) EGF-generated CNS progenitor cells. Neuron 11:951-966.

Weiss S, Dunne C, Hewson J, Wohl C, Wheatley M, Peterson AC, Reynolds BA (1996a) Multipotent CNS stem cells are present in the adult mammalian spinal cord and ventricular neuroaxis. J Neurosci 16:7599-7609.

Weiss S, Reynolds BA, Vescovi AL, Morshead C, Craig CG, van der Kooy D (1996b) Is there a neural stem cell in the mammalian forebrain? Trends Neurosci 19:387-393.

Xing J, Ginty DD, Greenberg ME (1996) Coupling of the RAS-MAPK pathway to gene activation by RSK2, a growth factor-regulated CREB kinase. Science 273:959-963. 